\title{
PENGARUH DEWAN KOMISARIS INDEPENDEN, KEPEMILIKAN MANAJERIAL, DEBT RATIO, LIKUIDITAS, DAN FAKTOR LAIN PADA KINERJA PERUSAHAAN MANUFAKTUR DI BEI DENGAN METODE TOBIN'S Q
}

\author{
Silviana \\ Program Studi Magister Manajemen Universitas Tarumanagara \\ silviana.117191041@stu.untar.ac.id \\ Sawidji Widoatmodjo \\ Program Studi Magister Manajemen Universitas Tarumanagara \\ Masuk : 06-11-2020, revisi : 21-12-2020 diterima untuk diterbitkan : 22-12-2020
}

\begin{abstract}
The study aims to gain empirical evidence about the effect of board independence, managerial ownership, debt ratio, liquidity, firm age, firm size, and firm growth to firm performance. Data sources come from manufacturing companies in Indonesia Stock Exchange (IDX) during 2014 to 2018 by using purposive sampling method. There are 48 samples selected as the final samples, then hypotheses tested by using multiple linear regression analysis. The conclusion of this study showed that debt ratio and firm size have positive significant to firm performance, but board independence, managerial ownership, liquidity, firm age, and firm growth do not significant to firm performance.
\end{abstract}

Abstrak: Penelitian ini bertujuan memperoleh bukti empiris terkait pengaruh dewan komisaris independen, kepemilikan manajerial, debt ratio, likuiditas, umur perusahaan, ukuran perusahaan, dan pertumbuhan perusahaan terhadap kinerja perusahaan. Sumber data dari perusahaan manufaktur di Bursa Efek Indonesia (IDX) selama 2014 hingga 2018 dengan menggunakan metode purposive sampling. Terdapat 48 sampel yang terpilih sebagai sampel akhir, kemudian hipotesis diuji menggunakan analisis regresi linear berganda. Kesimpulan dari hasil penelitian ini menunjukkan bahwa debt ratio dan ukuran perusahaan berpengaruh positif signifikan terhadap kinerja perusahaan, tetapi dewan komisaris independen, kepemilikan manajerial, likuiditas, umur perusahaan, dan pertumbuhan perusahaan tidak signifikan berpengaruh terhadap kinerja perusahaan.

Keywords: Firm Performance, Board Independence, Managerial Ownership, Debt Ratio, Liquidity, Firm Age, Firm Size, Firm Growth

\section{PENDAHULUAN}

Pola bisnis dunia yang ditandai dengan era globalisasi telah membawa keterbukaan perdagangan dunia, dimana kegiatan usaha terintegrasi dan berkembang menjadi lebih baik dengan arus teknologi informasi dan komunikasi yang serba cepat. Dengan diresmikannya ASEAN-China Free Trade Area (ACFTA) serta Masyarakat Ekonomi ASEAN (MEA) tahun 2016 mengakibatkan industri menjadi perhatian berbagai pelaku ekonomi. Maka perusahaan dituntut untuk menciptakan keunggulan kompetitif yang mampu membuat mereka bersaing di pasar domestik maupun global, yang akan mempengaruhi sudut pandang investor dalam melakukan Foreign Direct Investment (AbduRofiq, 2014).

Kinerja perusahaan menjadi perhatian untuk memicu ketertarikan investor, maka manajer diharapkan dapat memberikan indikasi kinerja perusahaan pada critical success factor. Hal ini dikarenakan kinerja perusahaan dapat mencerminkan kondisi perusahaan melalui pengukuran Tobin's Q yang diyakini menggambarkan aspek fundamental, tetapi juga sejauh mana pasar menilai keberhasilan perusahaan dalam pencapaian tujuan perusahaan dalam 
jangka waktu tertentu (Al-Materi et al, 2014). Permasalahan perusahaan di Indonesia ditandai dengan fluktuasi kinerja perusahaan, seperti PT. Bumi Resources, Tbk (BUMI) yang mengalami masalah perpajakan, kemudian berdampak pada kinerja perusahaannya yang disebabkan kurangnya pengawasan internal.

Maka dibutuhkan mekanisme corporate governance yang menjadi pilar perbaikan industri perusahaan dan diharapkan perusahaan dapat mematuhi peraturan yang berlaku. Komponen corporate governance salah satunya dewan komisaris independen yang bertugas sebagai pengawas perusahaan dalam mengontrol tindakan direksi dalam menjalankan perusahaan dan diharapkan perusahaan dapat membentuk tata kelola perusahaan yang baik, sekaligus menjamin sustainability perusahaan, serta secara tidak langsung menciptakan kinerja perusahaan yang baik (Komite Nasional Kebijakan Governance, 2006).

\section{Tujuan Penelitian}

Penelitian ini bertujuan memperoleh bukti empiris terkait pengaruh dewan komisaris independen, kepemilikan manajerial, debt ratio, likuiditas, umur perusahaan, ukuran perusahaan, dan pertumbuhan perusahaan terhadap kinerja perusahaan manufaktur yang terdaftar di Busa Efek Indonesia.

\section{TINJAUAN PUSTAKA}

\section{Teori Keagenan (Agency Theory)}

Teori keagenan adalah teori dimana terdapat perbedaan kepentingan antara pihak-pihak dalam hubungan keagenan yaitu agen dan principal dalam menjalankan perusahaan. Karena terdapat perbedaan kepentingan tersebut memicu konflik yang tak terelakkan, yang disebut konflik keagenan (agency conflict). Agen yang bertindak sebagai manajemen perusahaan, dimana dalam pelaksanaanya manajer dinilai cenderung bersifat oportunis karena memiliki tujuan memperkaya dirinya sendiri dan menyebabkan informasi asimetri. Berbeda dengan principal yang bertindak sebagai pemilik perusahaan atau pemegang saham bertujuan untuk memakmurkan dirinya dengan mempengaruhi keputusan manajemen untuk membuat nilai saham meningkat dan mengakibatkan peningkatan kinerja perusahaan (Jensen dan Meckling, 1976).

\section{Resources Based Theory}

Resources based theory adalah teori dimana perusahaan mengetahui kemampuan inti dari sumber daya yang dimilikinya (sumber daya fisik, manusia, organisasional) dan memanfaatkan secara maksimal untuk menciptakan competitive advantage. Ketika perusahaan dapat memaksimalkan sumber dayanya, terutama sumber daya manusia, maka perusahaan dapat mengatur strategi agar dapat bersaing dan memperoleh peluang dengan kekuatan inti perusahaan, yang akan mengakibatkan peningkatan kinerja perusahaan (Sari dan Priyadi, 2017).

\section{Teori Sinyal (Signalling Theory)}

Teori sinyal adalah teori yang menyatakan bahwa corporate insider (direktur dan manajer) yakin akan peluang perusahaan dan mengkomunikasikan keyakinannya kepada outsider (investor). Teori sinyal menimbulkan informasi asimetri yang mengakibatkan kacamata investor sulit membedakan mana informasi perusahaan yang high quality dan low quality (Wirianata, 2019).

Berikut pengembangan hipotesis berdasarkan hasil penelitian terdahulu.

\section{Kaitan Dewan Komisaris Independen dengan Kinerja Perusahaan}

Fungsi dewan komisaris independen sebagai pengawas perusahaan dan mengontrol tindakan direksi secara objektif dalam menjalankan perusahaan (Komite Nasional Kebijakan Governance, 2006). Tujuannya agar tercipta tata kelola perusahaan yang baik, sehingga akan berdampak pada kacamata investor yang merefleksikan kinerja perusahaan yang baik (Putra, 2015). Berdasar temuan di atas, maka dibangun hipotesis pertama:

\section{$\mathrm{H}_{1}$ : Dewan Komisaris Independen berpengaruh terhadap Kinerja Perusahaan}




\section{Kaitan Kepemilikan Manajerial dengan Kinerja Perusahaan}

Kepemilikan manajerial mengindikasikan manajemen menjalankan perusahaan, tetapi juga memegang saham perusahaan. Kepemilikan manajerial secara tidak langsung dapat meningkatkan kinerja perusahaan karena manajer memiliki saham perusahaan sehingga mempengaruhi pengambilan keputusan yang mengarah pada kesatuan tujuan dengan pemegang saham (Setiawan dan Fitria, 2015; Jensen dan Meckling, 1976; Lestari dan Juliarto, 2017). Berdasar temuan di atas, maka dibangun hipotesis ke-dua:

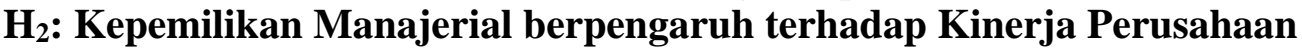

Kaitan Debt Ratio dengan Kinerja Perusahaan

Perusahaan yang memperoleh peningkatan pendanaan dari utang memiliki kewajiban untuk membayar pokok pinjaman dan bunga, sehingga peran utang dapat memotivasi manajer untuk bekerja lebih baik dalam meningkatkan kinerja perusahaan (Rashid, 2011; Jensen dan Meckling, 1976). Berdasar temuan di atas, maka dibangun hipotesis ke-tiga:

\section{$\mathrm{H}_{3}$ : Debt Ratio berpengaruh terhadap Kinerja Perusahaan}

\section{Kaitan Likuiditas dengan Kinerja Perusahaan}

Perusahaan yang mampu memenuhi kewajiban jangka pendeknya dengan baik, cenderung dapat memberikan sinyal positif kepada investor karena perusahaan dapat melunasi kewajiban jangka pendek dengan aset lancarnya yang mengindikasikan perusahaan beroperasi dan berkinerja dengan baik (Lestari dan Juliarto, 2017; Lestari dan Sampurno, 2017). Berdasar temuan di atas, maka dibangun hipotesis ke-empat:

\section{H4: Likuiditas berpengaruh terhadap Kinerja Perusahaan \\ Kaitan Umur Perusahaan dengan Kinerja Perusahaan}

Umur perusahaan yang lama menunjukkan citra perusahaan dimata masyarakat karena perusahaan memiliki kemampuan dan keahlian daripada perusahaan yang baru berdiri. Hal ini sesuai dengan tujuan perusahaan untuk mempertahankan sustainability perusahaan. Maka semakin lama umur perusahaan menunjukkan peningkatan kinerja perusahaan pula (Lestari dan Juliarto, 2017; Mukhopadhyay dan Chakraborty, 2017). Berdasar temuan di atas, maka dibangun hipotesis ke-lima:

\section{H5: Umur Perusahaan berpengaruh terhadap Kinerja Perusahaan Kaitan Ukuran Perusahaan dengan Kinerja Perusahaan}

Ukuran perusahaan yang besar juga memiliki kapasitas yang lebih besar dalam menghasilkan dana internal. Selain itu, perusahaan besar memiliki kondisi yang lebih stabil dan memiliki unit bisnis yang banyak, sehingga akan mengakibatkan profitabilitas yang tinggi. Hal ini akan menarik investor yang berdampak pada peningkatan harga saham serta berakibat pula pada peningkatan kineja perusahaan (Alvarado dan Bravo, 2017). Berdasar temuan di atas, maka dibangun hipotesis ke-enam:

\section{$\mathrm{H}_{6}$ : Ukuran Perusahaan berpengaruh terhadap Kinerja Perusahaan Kaitan Pertumbuhan Perusahaan dengan Kinerja Perusahaan}

Pertumbuhan perusahaan yang dilihat dari peningkatan penjualan akan menunjukkan bahwa produk perusahaan yang dijual diterima oleh pasar, sehingga peningkatan laba dapat mencerminkan kinerja perusahaan yang baik (Lestari dan Sampurno, 2017; Alvarado dan Bravo, 2017). Berdasar temuan di atas, maka dibangun hipotesis ke-tujuh:

\section{H7$_{7}$ : Pertumbuhan Perusahaan berpengaruh terhadap Kinerja Perusahaan}

\section{METODOLOGI PENELITIAN}

Subjek penelitian merupakan populasi pada perusahaan manufaktur yang terdaftar di Bursa Efek Indonesia selama 2014-2018. Objek penelitian ini terdiri dari tujuh variabel independen (dewan komisaris independen, kepemilikan manajerial, debt ratio, likuiditas, umur perusahaan, ukuran perusahaan, pertumbuhan perusahaan) dan satu variabel dependen yaitu kinerja perusahaan. Sampel penelitian ini diperoleh dengan metode purposive sampling dan terdapat 48 sampel yang terpilih sebagai sampel akhir. Jenis uji yang digunakan dalam 
penelitian ini terdapat uji statistik deskriptif, uji kualitas data, uji asumsi klasik, dan uji hipotesis dengan menggunakan analisis regresi linear berganda.

\section{Tabel 1}

Operasionalisasi Variabel

\begin{tabular}{|c|l|l|}
\hline No. & Variabel & Definisi Operasional \\
\hline 1. & $\begin{array}{l}\text { Variabel Dependen } \\
\text { Kinerja Perusahaan }\end{array}$ & Tobin's Q \\
\hline 2. & $\begin{array}{l}\text { Variabel Independen } \\
\text { Dewan Komisaris } \\
\text { Independen }\end{array}$ & $\begin{array}{l}\text { Proporsi dewan komisaris yang dinyatakan sebagai komisaris } \\
\text { independen di laporan tahunan perusahaan. }\end{array}$ \\
\hline 3. & Kepemilikan Manajerial & $\begin{array}{l}\text { Proporsi kepemilikan saham perusahaan yang dimiliki oleh pihak } \\
\text { manajemen terhadap jumlah saham yang beredar. }\end{array}$ \\
\hline 4. & Debt Ratio & Perbandingan seberapa besar aset perusahaan yang dibiayai oleh utang. \\
\hline 5. & Likuiditas & $\begin{array}{l}\text { Rasio seberapa besar kemampuan perusahaan dalam memenuhi liabilitas } \\
\text { lancar dengan aset lancar yang tersedia. }\end{array}$ \\
\hline 6. & Umur Perusahaan & Lamanya perusahaan berdiri \\
\hline 7. & Ukuran Perusahaan & $\begin{array}{l}\text { Besar kecilnya perusahaan yang diukur dari aset yang dimiliki } \\
\text { perusahaan. }\end{array}$ \\
\hline 8. & Pertumbuhan Perusahaan & $\begin{array}{l}\text { Selisih penjualan tahun t dengan tahun sebelumnya (t-1) dibandingkan } \\
\text { dengan penjualan tahun sebelumnya. }\end{array}$ \\
\hline
\end{tabular}

\section{HASIL DAN KESIMPULAN}

\section{Tabel 2}

\section{Hasil Statistik Deskriptif}

\begin{tabular}{llllll}
\hline Variabel & $\mathrm{N}$ & Mean & Minimum & Maksimum & Std. Deviation \\
\hline TOBINS_Q & 240 & 1,429033 & 0,304145 & 7,111081 & 1,061009 \\
BDIND & 240 & 0,400282 & 0,000000 & 1 & 0,096393 \\
MOWN & 240 & 0,099542 & 0,000000 & 0,894444 & 0,187964 \\
DEBT & 240 & 0,523357 & 0,000484 & 3,593281 & 0,410246 \\
LIQ & 240 & 2,421267 & 0,033705 & 15,164601 & 2,217788 \\
AGE & 240 & 37,333000 & 17 & 67 & 9,927200 \\
SIZE & 240 & 12,178816 & 11,001396 & 14,537455 & 0,709780 \\
GROWTH & 240 & 0,053916 & $-0,986759$ & 1,678099 & 0,240426 \\
\hline
\end{tabular}

Sumber: Output Data SPSS 23

Setelah uji statistik deskriptif, dilakukan uji normalitas data residual dengan menggunakan One-Sample Kolmogorov-Smirnov Test, dimana nilai Asymp. Sig (2-tailed) sebesar $0,000<0,05$, maka dapat disimpulkan bahwa data sampel tidak terdistribusi secara normal. Kemudian dilakukan uji asumsi klasik, pertama uji autokorelasi menggunakan uji Breusch-Godfrey dan didapatkan nilai signifikansi lag residual sebesar 0,002 < 0,05, maka disimpulkan bahwa terdapat autokorelasi. Kedua, uji multikolinieritas didapatkan hasil tidak terjadi multikolinieritas. Ketiga, uji heteroskedastisitas dimana dewan komisaris independen, debt ratio, umur perusahaan, pertumbuhan perusahaan tidak terjadi heteroskedastisitas. Sedangkan kepemilikan manajerial, likuiditas, ukuran perusahaan terjadi heteroskedastisitas. Terakhir uji hipotesis yang dapat dilihat pada tabel berikut:

\section{Tabel 3}

Hasil Uji t

\begin{tabular}{lllll}
\hline Variabel & $\mathrm{B}$ & $\mathrm{T}$ & Sig. & Kesimpulan \\
\hline (Constant) & $-4,292$ & $-3,152$ & 0,002 & \\
BDIND & 1,277 & 1,834 & 0,068 & $\mathrm{Ha}_{1}$ tidak diterima \\
MOWN & $-0,574$ & $-1,523$ & 0,129 & $\mathrm{Ha}_{2}$ tidak diterima \\
DEBT & 0,463 & 2,503 & 0,013 & $\mathrm{Ha}_{3}$ diterima \\
LIQ & 0,047 & 1,367 & 0,173 & $\mathrm{Ha}_{4}$ tidak diterima \\
AGE & $-0,004$ & $-0,528$ & 0,598 & $\mathrm{Ha}_{5}$ tidak diterima \\
SIZE & 0,416 & 3,701 & 0,000 & $\mathrm{Ha}_{6}$ diterima \\
GROWTH & $-0,150$ & $-0,529$ & 0,598 & $\mathrm{Ha}_{7}$ tidak diterima \\
\hline
\end{tabular}

Sumber: Output Data SPSS 23 


\section{Kesimpulan}

Berdasarkan hasil penelitian hipotesis ke-tiga dan ke-enam diterima, yaitu debt ratio dan ukuran perusahaan berpengaruh positif signifikan terhadap kinerja perusahaan. Penelitian ini konsisten dengan penelitian Rashid, 2018; Lestari dan Juliarto, 2017. Sedangkan variabel dewan komisaris independen, kepemilikan manajerial, likuiditas, umur perusahaan, dan pertumbuhan perusahaan tidak signifikan mempengaruhi kinerja perusahaan. Saran dalam penelitian ini berdasarkan kesimpulan di atas, karena hipotesis ke-tiga dan ke-enam diterima, sebaiknya perusahaan dapat melirik untuk menggunakan debt sebagai motivasi untuk meningkatkan kinerja perusahaan. Perusahaan disarankan meningkatkan ukuran perusahaan dengan cara meningkatkan total aset supaya perusahaan memiliki sumber dana yang besar, sehingga perusahaan dapat memproduksi barang dalam jumlah massal dan otomatis memiliki unit bisnis yang banyak sehingga perusahaan akan lebih stabil dalam menghasilkan profitabilitas. Secara tidak langsung ukuran perusahaan yang besar menunjukkan kinerja perusahaan yang baik.

\section{REFERENCES}

AbduRofiq, A. (2014). Menakar pengaruh masyarakat ekonomi Asean 2015 terhadap pembangunan Indonesia. Jurnal Filsafat dan Budaya Hukum, 1, 249-256.

Al-Matari, E. M., Al-Swidi, A. K., \& Bt Fadzil, F. H. (2014). The measurements of firm performance's dimensions. Asian Journal of Finance and Accounting, 6(1).

Jensen, M. C., \& Meckling, W. H. (1976). Theory of the firm: Managerial behavior, agency costs and ownership structure. Journal of Financial Economics, 3(4), 305-360.

Komite Nasional Kebijakan Governance. (2006). Pedoman Umum Good Corporate Governance. Jakarta: KNKG.

Lestari, E. P., \& Sampurno, R. D. (2017). Analisis faktor-faktor yang mempengaruhi kinerja perusahaan. Diponegoro Journal of Management, 6(3), 1-12.

Mukhopadhyay, J., \& Chakraborty, I. (2017). Foreign institutional investment, business groups and firm performance: Evidence from India. International Research Journal of Business and Finance, 39(1), 454-465.

Rashid, A. (2011). Corporate governance in Bangladesh: A quest for the accountability or legitimacy crisis? Research in Accounting in Emerging Economies, 11(1), 1-34.

Rashid, A. (2018). Board independence and firm performance: Evidence from Bangladesh. Future Business Journal, 4, 34-49.

Sari, A. P., \& Priyadi, M. P. (2017). Pengaruh intellectual capital dan corporate governance terhadap kinerja perusahaan. Jurnal Ilmu dan Riset Akuntansi, 6(7), 1-20.

Wirianata, H. (2019). Faktor-faktor yang mempengaruhi nilai perusahaan dengan moderasi CGC. Jurnal Ekonomi, 24(3), 468-487. 